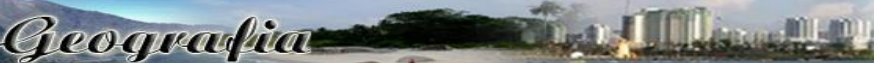

Malaysian Tournal of Society and Space

\section{Perancangan dan pengurusan landskap di Klebang, Melaka}

\author{
Rosniza Aznie Che Rose ${ }^{1} \&$ Siti Azah Abdul Ghani ${ }^{1}$ \\ ${ }^{1}$ Program Geografi, Pusat Kajian Pembangunan, Sosial \& Persekitaran (SEEDS) \\ Fakulti Sains Sosial \& Kemanusiaan, Universiti Kebangsaan Malaysia \\ Correspondence: Rosniza Aznie Che Rose (email: aznie@ukm.edu.my)
}

Received: 08 October 2019; Accepted: 03 February 2020; Published: 30 May 2020

\begin{abstract}
Abstrak
Perancangan dan pengurusan landskap memainkan peranan yang penting dalam memastikan kelestarian landskap dalam pembangunan sesebuah kawasan rekreasi. Perlaksanaan perancangan landskap yang terancang dapat meningkatkan kualiti kawasan rekreasi dan dalam masa yang sama memastikan keharmonian masyarakat terpelihara. Kajian ini bertujuan untuk mengenal pasti tahap kemudahan dan elemen landskap sama ada mencukupi atau tidak. Selain itu, kajian ini juga mengkaji tahap kepuasan masyarakat terhadap perancangan landskap serta memberikan cadangan konsep pembangunan landskap yang sesuai di kawasan kajian. Kawasan kajian yang dipilih ialah Dataran 1Malaysia Klebang, Melaka. Kaedah kajian yang digunakan iaitu temu bual informal, kaedah soal selidik dan pemerhatian di lapangan. Sampel kajian yang diambil ialah seramai 80 orang responden berdasarkan teknik persampelan rawak mudah. Dapatan kajian menunjukkan bahawa aspek perancangan, pembangunan, perlaksanaan dan pengurusan landskap di kawasan kajian berada di tahap sederhana dan perlu diperbaiki untuk mencapai tahap kelestarian yang lebih baik. Beberapa cadangan penambahbaikan seperti penambahan terhadap pokok teduhan dan renek yang mencukupi, pembangunan elemen air, penambahbaikan laluan pejalan kaki, penambahbaikan terhadap perabot taman dan elemen landskap kejur dan elemen landskap lembut di sekitar kawasan kajian. Ini penting untuk memastikan matlamat asal penubuhan kawasan rekreasi sebagai kawasan riadah serta untuk kesejahteraan hidup masyarakat dapat dicapai.
\end{abstract}

Kata kunci: kesejahteraan, landskap, pembangunan, pengurusan persekitaran, perancangan

\section{Landscape Planning and Management at Klebang, Melaka}

\begin{abstract}
Landscape planning and management play important roles in creating a sustainable landscape in a recreational area. A well-planned landscape implementation can create a high quality recreational area and at the same time, can keep a community harmonious. The study is to identify whether the landscape facilities and elements are sufficiently provided. Also to
\end{abstract}


identify whether the community is truly satisfied with the landscape planning and if they have suggestion on the suitable landscape development concept upon the area. The chosen site is Dataran 1Malaysia Klebang, Melaka. Informal interviews, series of questionnaire and field observation were some of the data collecting methods used during the study. The sample of the study was 80 respondents based on simple random sampling technique. The findings of the study showed that the landscape planning, implementation, development, and management of the area are at the average level and need to be improved and enhanced to achieve a better and sustainable landscape condition. Several enhancements have been suggested such as, sufficient numbers of trees and shrubs must be planted, developing water elements, enhancement of pedestrian walkway and landscape furniture, and overall hardscape and softcape elements over the study area. This is very important to ensure that the first goal of developing the recreational area as a place to exercise plus for the wellbeing of the community is accomplished.

Keywords: wellbeing, landscape, development, environmental management, planning

\section{Pengenalan}

Senibina landskap sering dibahagikan kepada tiga fasa atau tugas iaitu perancangan, reka bentuk dan pengurusan. Projek seni bina landskap biasanya berkembang secara kronologi dan hierarki iaitu ia bermula daripada rancangan yang ditetapkan oleh pihak berkuasa untuk mereka bentuk landskap yang lebih terperinci. Kemudian, direalisasikan melalui pembinaan atau penanaman, dan dengan amalan pengurusan dilaksanakan sebagai 'fasa akhir'. Konvensyen antarabangsa sering menetapkan penyertaan awam dalam perancangan dan pengurusan sesuatu landskap. Banyak konsep dan perspektif tentang penglibatan pengguna yang berbeza-beza dalam pelbagai skala, pengagihan kuasa dan keupayaan pengetahuan telah dicadangkan. Walau bagaimanapun, penglibatan pengguna dalam proses pembangunan bersama sering bergantung kepada apa yang dilakukan oleh pihak berkuasa tempatan (Jansson et al., 2019).

Salah satu tarikan aktiviti pelancongan rekreasi di sesebuah kawasan adalah dari segi tarikan landskapnya sama ada landskap semula jadi atau buatan. Bagi negeri Melaka, sektor pelancongan rekreasi memainkan peranan penting dalam membantu menjana ekonomi negeri. Pengiktirafan Bandar Melaka sebagai 'Bandaraya Warisan Dunia' oleh UNESCO pada tahun 2008 umumnya telah membantu meningkatkan lagi prestasi pelancongan rekreasi di Melaka pada tahap yang lebih memberangsangkan. Keadaan ini dapat dilihat melalui perkembangan aktiviti pelancongan yang semakin rancak dipromosikan dari tahun ke tahun. Selaras dengan moto 'Melawat Melaka Bersejarah bererti Melawat Malaysia', pihak kerajaan negeri Melaka dan swasta telah menjalankan pelbagai aktiviti dan mewujudkan pelbagai kawasan pelancongan rekreasi untuk menarik ramai pelancong dari luar dan dalam negara untuk melawat negeri Melaka. Hal ini bertujuan menjadikan negeri Melaka membangun seiring dengan pembangunan yang berlaku di Malaysia. Terbaharu, kerajaan negeri Melaka telah mengambil inisiatif membangunkan satu produk pelancongan rekreasi iaitu Dataran 1Malaysia Klebang, Melaka sebagai kawasan tumpuan pelancong.

Keperluan masyarakat kepada aktiviti rekreasi semakin ketara daripada peningkatan dalam mutu pendidikan dan status ekonomi. Bagi mewujudkan satu persekitaran kehidupan yang sihat, selesa dan menarik, penyelenggaraan kawasan taman dan rekreasi adalah penting dan perlu diberi perhatian yang serius serta diurus oleh pihak kerajaan. Dengan mewujudkan kawasan rekreasi yang menarik dan berfungsi, ia boleh meningkatkan imej sesebuah bandar atau pihak berkuasa tempatan (PBT). Menurut Wan Mohammad (1995), pendekatan 
penyelenggaraan landskap boleh meningkatkan penampilan yang baik dan jangka hayat sesuatu tapak kemudahan yang sedia ada. Oleh itu, pihak kerajaan perlu menekankan aspek penyelenggaran terhadap kawasan-kawasan rekreasi yang dibangunkan dengan menerapkan penyelenggaran landskap yang terperinci. Oleh yang demikian dalam menjadikan satu kawasan rekreasi sebagai kawasan tumpuan pelancong, kajian perancangan dan pengurusan adalah perlu dilakukan untuk memastikan sesebuah taman rekreasi itu dikunjungi ramai. Selain itu, rekabentuk pembangunan persekitaran perlulah diuruskan dengan baik dan sistematik.

Perancangan, perlaksanaan dan pengurusan landskap merupakan tonggak penting dalam menjayakan sesuatu kawasan pelancongan rekreasi. Walaupun perkembangan landskap telah wujud di kawasan kajian dan menghasilkan beberapa perubahan alam semula jadi. Namun begitu, masih terdapat kelemahan di dalam perancangan landskap. Penyediaan landskap di sesebuah taman rekreasi awam merupakan salah satu kemudahan yang disediakan oleh PBT khususnya kepada komuniti bandar. Pengurusan landskap yang baik dan berkualiti akan mempengaruhi kunjungan dan tahap kepuasan pengunjung. Walau bagaimanapun, pengurusan landskap di kebanyakan taman awam secara umumnya masih berada pada tahap yang rendah. Dalam hal ini, kajian mengenai persepsi masyarakat terhadap pelaksanaan perancangan landskap di kawasan pelancongan rekreasi iaitu di Dataran 1Malaysia, Klebang, Melaka ini telah dilakukan untuk mengenal pasti isu dan masalah yang timbul di kawasan kajian.

\section{Kajian literatur}

Taman rekreasi merupakan salah satu kemudahan fasiliti yang perlu disediakan oleh PBT dan menjadi satu keperluan hidup bagi setiap lapisan masyarakat terutamanya komuniti bandar. Kewujudan taman rekreasi merupakan salah satu elemen penting di dalam pembangunan sesebuah kawasan kerana ia menyediakan kemudahan khas kepada orang awam untuk berekreasi dan beriadah secara percuma. Penyediaan taman rekreasi, menurut Jubenville dan Ben (1993), adalah sebagai salah satu elemen di dalam sistem sosial yang membantu menggalakkan pertumbuhan semangat kekitaan (integrity). Taman rekreasi merupakan sebahagian daripada tanah lapang yang termaktub dalam Akta Perancangan Bandar dan Desa 1976 (Akta 172). Tanah lapang telah ditafsirkan sebagai mana-mana tanah sama ada yang dikepung atau yang tidak disusun atur atau dirizabkan untuk disusun atur keseluruhannya atau sebahagiannya sebagai suatu taman bunga awam, taman awam, padang sukan dan rekreasi awam, tempat makan angin awam, tempat jalan kaki awam atau sebagai suatu tempat awam. Tanah lapang dan rekreasi adalah saling berkaitan. Tanah lapang merupakan suatu ruang atau tapak yang dikhaskan untuk tujuan seperti yang telah ditetapkan oleh akta. Manakala rekreasi pula merupakan aktiviti yang dijalankan di atas mana-mana tanah lapang. Tanah lapang dan rekreasi adalah merupakan satu kawasan awam yang digunakan untuk tujuan riadah yang tidak dikenakan sebarang bayaran masuk.

Kemudahan kawasan lapang dan rekreasi memainkan peranan penting dalam menggalakkan penduduk setempat mengamalkan gaya hidup sihat dan secara tidak langsung ia menjadi daya tarikan pelancongan bagi sesebuah kawasan. Tarikan terhadap kawasan ini adalah dipengaruhi oleh reka bentuk taman, jenis aktiviti, tahap penyelenggaraan dan kualiti kemudahan sokongan yang ditawarkan oleh kawasan pelancongan rekreasi tersebut. Pembangunan secara lestari adalah proses membuat keputusan bersama oleh pihak yang berkepentingan dalam merancang pembangunan wilayah seperti PBT, badan bukan kerajaan, persatuan perniaga setempat dan pengguna bagi memastikan aktiviti ekonomi, kebajikan penduduk (termasuk kesihatan) dan ekosistem sama-sama diberi pertimbangan tersepadu bagi 
memastikan generasi kini dan akan datang dapat memenuhi keperluannya secara berterusan (Er et al., 2015).

\section{Pengurusan landskap}

Landskap adalah tahap spatial yang ideal untuk menguruskan sesebuah kawasan kerana banyak proses dan gangguan ekologi berlaku pada skala tersebut. Selain itu, proses pembuatan keputusan peringkat landskap dapat meningkatkan kecekapan pengurusan, seperti usaha pemilik petak kecil dalam meningkatkan ekonomi skala operasi mereka dengan menyewa atau menjual produk bersama. Pengurusan adalah proses sesebuah organisasi yang merangkumi perancangan strategik, penetapan objektif, pengurusan sumber, penggunaan tenaga kerja dan aset kewangan yang diperlukan untuk mencapai objektif, dan mengukur keputusan (Fischer et al., 2019).

Deborah dan Andrew (2008) menjelaskan bahawa bagaimana peningkatan taman kontemporari, pengubahsuaian, dan reka bentuk boleh menangani keperluan masyarakat mendesak hari ini. Kajian tersebut menunjukkan kekerapan masyarakat ke sesebuah taman disebabkan beberapa faktor iaitu seperti persekitaran yang selesa, reka bentuk taman yang menarik dan kemudahan yang mencukupi. Hasil dapatan kajian menyenaraikan beberapa aspek yang perlu dititikberatkan oleh pengurus taman iaitu persekitaran taman dari segi keperluan dan komposisi taman. Kedua, ruang taman perlu direka untuk mewujudkan peluang untuk interaksi sosial dalam kalangan individu dari semua peringkat umur. Ketiga, pengurus taman perlu mengetahui bahawa taman-taman awam dan kawasan rekreasi adalah sebahagian daripada landskap masyarakat dan sering mewujudkan pelbagai faedah dari segi fizikal, sosial, dan kebudayaan untuk para pelawat. Keempat adalah berkaitan dengan faktor keselamatan para pengunjung. Oleh itu, pengurus perlu mengekalkan standard keselamatan bagi peralatan dan reka bentuk taman-taman mereka dan ruang bermain untuk mengurangkan risiko kepada pengguna.

\section{Penyelenggaraan landskap}

Angelstam et al. (2019) menyatakan bahawa The Council of Europe telah mentakrifkan landskap sebagai ruang integrasi sosial dan ekologi iaitu kawasan seperti yang dilihat oleh manusia, yang wataknya adalah akibat daripada tindakan dan interaksi faktor-faktor semula jadi dan/atau manusia. Ia merupakan pertimbangan secara menyeluruh terhadap tafsiran biofizikal, antropogenik dan tidak ketara terhadap landskap pada pelbagai skala mewakili pendekatan holistik untuk mendapatkan peruntukan perkhidmatan ekosistem. Ini memerlukan pengekalan terhadap infrastruktur fungsional ekologi, atau hijau melalui perancangan ruang (Angelstam et al., 2017; 2018), dan pengurusan landskap ke arah pengurusan penggunaan tanah bersepadu (Bieling \& Plieninger, 2017). Apabila landskap telah berubah secara intensif untuk menyampaikan hanya satu jenis perkhidmatan ekosistem, kerosakan kawasan persekitaran (ekosistem) mungkin berlaku (Potschin \& Haines-Young, 2013; Deng et al., 2016; Locatelli et al., 2017).

Penyelenggaraan landskap adalah keadaan landskap yang sentiasa berubah dengan keperluan manusia seiring permintaan (Thompson \& Sorvig, 2000). Abdul Haris (2013) menyatakan penyelenggaraan landskap adalah berkenaan dengan penjagaan rutin tanah, tumbuhan dan permukaan keras (landskap kejur) mengikut cara yang ditetapkan demi keberlangsungan masa hadapan. Menurut Osman (2002), kualiti alam sekitar yang baik dapat diperoleh melalui kualiti pembangunan dan pengurusan yang sempurna termasuk aspek penyelenggaraan landskap yang berkualiti. Taman rekreasi yang telah siap dibina dan digunakan oleh orang awam perlu diselenggara bagi memastikan fungsi serta matlamat 
menyediakan kemudahan dapat dikekalkan serta tidak mendatangkan bahaya kepada pengguna. Selain itu, penyelenggaraan adalah diperlukan bagi memastikan semua kemudahan yang disediakan adalah tahan lama dan sentiasa selamat dan menarik. Namun, hayat sesuatu kemudahan adalah juga bergantung kepada cara dan kekerapan diselenggara.

Menurut More (1989), pendekatan penyelenggaraan landskap yang teratur boleh meningkatkan penampilan yang baik terhadap kemudahan fasiliti sedia ada dan menjurus kepada kewujudan imej kawasan rekreasi yang baik. Faktor-faktor yang berkaitan dengan positif imej taman termasuk pengetahuan ciri-ciri taman yang tepat, kemudahan akses, kemudahan tertentu yang berkaitan dengan kepentingan rekreasi, landskap semula jadi yang menarik dan penyelenggaraan yang baik secara keseluruhan.

Sementara itu, kajian Goh dan Noratiqah (2016) mendedahkan persepsi pengguna tentang peranan Taman Botanikal Perdana untuk tujuan rekreasi. Taman Botanikal Perdana telah menjadi ikon penting dalam sejarah taman-taman awam di negara ini khususnya untuk Bandaraya Kuala Lumpur. Kajian yang telah dijalankan mendapati Taman Botanikal Perdana mampu mengekalkan kualiti dalam pengurusan dan penyelenggaraan taman. Melalui dapatan kajian menunjukkan bahawa pengguna berpuas hati dengan aktiviti dan kemudahan yang ditawarkan di taman kecuali kemudahan tempat letak kenderaan terutamanya apabila lokasi tidak berada dalam jarak berjalan kaki bagi kebanyakan pengguna. Lanjutan dari itu, ia mendedahkan bahawa peranan Taman Botanikal Perdana sebagai tarikan pelancongan telah memberi manfaat kepada pengguna terutama dari segi pengurusan, penyelenggaraan dan aktiviti diwujudkan.

\section{Penilaian masyarakat terhadap perancangan dan pengurusan landskap}

Kajian berkaitan kepuasan pelawat terhadap kawasan rekreasi pernah dilakukan oleh Noralizawati dan Noriah (2010). Kajian ini dijalankan di kawasan rekreasi paling popular iaitu Taman Metropolitan Kepong, Selangor. Melalui hasil kajian ini, dapat disimpulkan bahawa unsur-unsur semula jadi di Taman Metropolitan Kepong digunakan untuk mengetahui tahap kepuasan pengunjung. Antara faktor-faktor yang mempengaruhi atau menarik minat pengunjung untuk melawat kawasan rekreasi adalah dikaitkan dengan elemen yang cantik, elemen penyejukan dan juga penghargaan pengunjung terhadap pemeliharaan haiwan. Selain ciri-ciri fizikal, nilai dan manfaat daripada bidang-bidang seperti keamanan, ketenangan, kelegaan tekanan dan pendekatan dengan alam semula jadi juga dikaitkan dengan perasaan kepuasan mereka.

Faktor lain yang mempengaruhi kepuasan pengunjung adalah dari aspek penyelenggaraan dan pengurusan kawasan tersebut. Jelas sekali, persekitaran yang tidak selamat akan memberikan kesan negatif ke atas kepuasan pengunjung. Melalui kajian ini diharapkan bahawa unsur-unsur semula jadi yang diabaikan di kawasan kajian ini boleh dinaik taraf supaya ia dapat menangani kepuasan pengunjung dengan cara yang positif pada masa hadapan.

Seterusnya, terdapat tiga cabaran utama untuk mengintegrasikan nilai sosial dalam penilaian ekosistem iaitu kesukaran untuk mengkuantifikasi nilai yang tidak material; kesukaran dalam menghubungkannya dengan sistem tertentu atau perubahan landskap; dan hakikat bahawa faedah mungkin dikaitkan dengan sebarang perkhidmatan dan bukan terhad kepada faktor budaya sahaja (Verbrugge et al., 2019). Banyak faktor sosial dan demografi yang berbeza telah ditunjukkan untuk mempengaruhi persepsi masyarakat terhadap landskap. Usia dan kebiasaan atau rutin harian diperhatikan sebagai pengaruh yang tinggi dalam perilaku pemilihan kawasan rekreasi. Menurut Verbrugge et al. (2019) lagi, antara pengaruh lain terhadap persepsi landskap ialah kesedaran mengenai sejarah/kebudayaan; nama-nama 
terkenal; persekitaran sosial dan budaya; pendidikan; pengalaman; dan pengetahuan tentang landskap.

Selain itu, menurut Dearden (1981), masyarakat tempatan dilihat sebagai individu atau kumpulan yang kurang arif dalam menilai sesuatu landskap kerana mempunyai penilaian yang subjektif dan secara peribadi. Walau bagaimanapun, para penyelidik yang telah menggunakan orang ramai sebagai subjek kajian penilaian landskap telah mendapati mereka sangat bermotivasi, berminat dalam topik itu dan bersedia meluangkan masa mereka tanpa mengira latar belakang sosial, ekonomi dan pendidikan (Dearden, 1981). Justeru, penilaian terhadap perancangan dan pengurusan sesuatu landskap perlu mengambil kira pandangan orang ramai memandangkan mereka yang akan mengunakan kemudahan tersebut.

\section{Kawasan kajian dan metod}

Kawasan kajian iaitu Pantai Klebang, Melaka telah dipilih disebabkan kawasan tersebut menjadi tumpuan orang ramai untuk beriadah dan bersantai memandangkan kawasan tersebut mempunyai pelbagai tarikan. Bersesuaian dengan pembinaan Dataran 1Malaysia Klebang, Melaka yang diwujudkan di kawasan yang berbentuk lagun, terdapat ciri-ciri dan isu yang berkaitan yang terdapat di situ sesuai dijadikan sebagai penanda aras kepada strategi pengurusan landskap kawasan rekreasi.

\section{Latar belakang kawasan kajian}

Dataran 1Malaysia Klebang ini terletak di Pantai Klebang yang terletak dalam daerah Melaka Tengah. Dataran 1Malaysia Klebang merupakan salah satu elemen hijau buatan yang diwujudkan di Melaka di atas kawasan tambak laut seluas 38.41 ekar. Kawasan ini adalah salah satu tempat tumpuan yang menjadi inisiatif kerajaan untuk menjadikan kawasan persekitaran hijau dan mengekalkan serta memulihara alam sekitar untuk generasi akan datang. Ia merupakan kategori taman peringkat tempatan yang boleh dijalankan dengan pelbagai aktiviti rekreasi, sukan dan kegiatan sosial penduduk setempat dan pengunjung dari luar kawasan. Dataran 1Malaysia Klebang Melaka yang berwajah baru ini diwujudkan di kawasan pantai berbentuk lagun.

Dahulunya Pantai Klebang 'sunyi sepi' daripada sebarang aktiviti riadah berikutan kawasan persisiran pantainya ditambak hingga menyebabkan ia tidak lagi menjadi tumpuan. Kini, banyak tarikan yang ada di Dataran 1Malaysia Klebang dan salah satu tarikan utamanya ialah deretan restoran bas yang disusun oleh Majlis Bandaraya Melaka Bersejarah (MBMB) di sepanjang laluan memasuki kawasan tersebut (Rajah 1). Keunikannya bas-bas lama tersebut dijadikan restoran tanpa mengubah fizikal dan cat asal kecuali bahagian dalam bas. Di dalam bas itu juga pemilik premis memasak untuk pelanggan dan menyediakan ruang makan untuk para pelanggan menikmati pelbagai juadah. Restoran bas yang menghadap laut Selat Melaka itu ternyata menambah daya tarikan di kawasan tersebut. Selain itu, penginapan di dalam bas atau dikenali sebagai Bustel turut disediakan untuk pengunjung beristirehat. Sebanyak 16 buah bas lama telah diubahsuai untuk dijadikan penginapan yang lengkap dengan katil, penghawa dingin, bilik mandi, almari dan bilik air. Terdapat juga aktiviti perkhidmatan kereta kuda, jentera lasak ATV, beca dan permainan layang- layang yang menambah nilai aktiviti rekreasi di kawasan ini. 


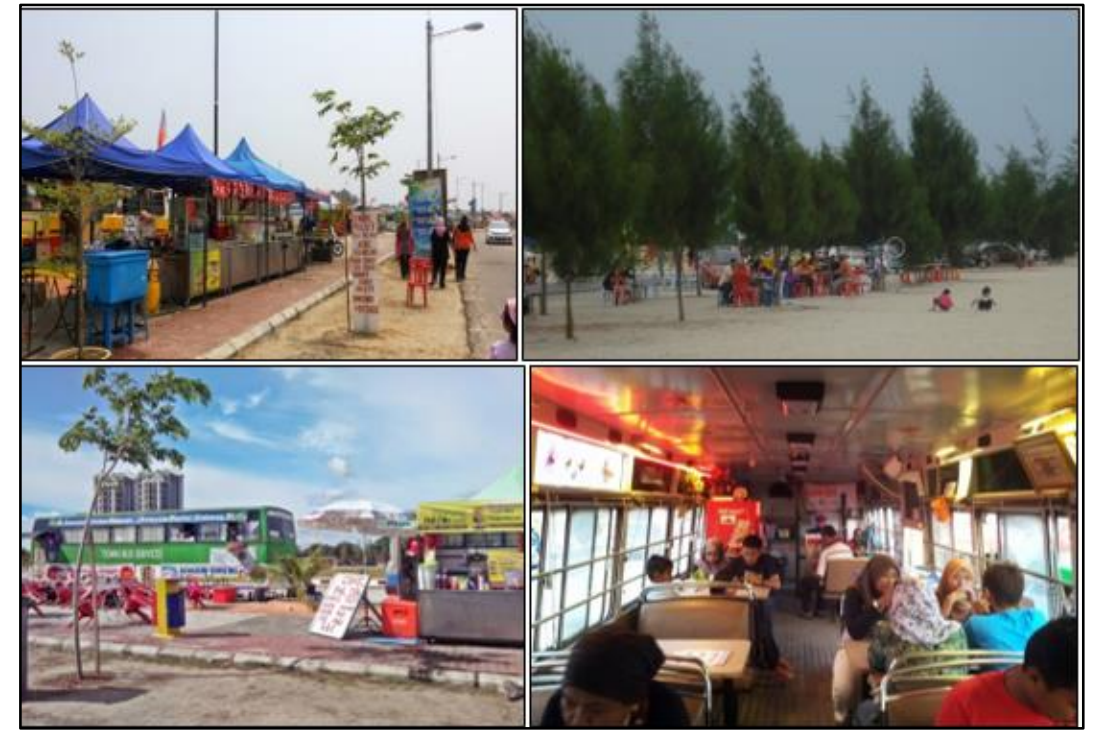

Sumber: Kajian lapangan (2017)

Rajah 1. Kemudahan gerai makanan yang disediakan di Dataran 1Malaysia Klebang

\section{Kaedah pemilihan sampel}

Kaedah persampelan yang digunakan dalam kajian ini adalah persampelan kebarangkalian dengan memilih kaedah persampelan rawak mudah. Kaedah ini dipilih agar responden yang dipilih adalah memenuhi syarat kajian iaitu peniaga yang berniaga di Dataran 1Malaysia Klebang dan pengunjung. Namun penetapan bilangan sampel turut diambil kira dalam kajian ini agar analisis dapat dilakukan mengikut objektif kajian. Jika berdasarkan data, jumlah populasi iaitu bilangan pengunjung lebih kurang 100 orang sehari di kawasan kajian. Jika berpandukan jadual penetapan dan pengiraan Krejcie dan Morgan (1970) bilangan sampel yang diperlukan adalah seramai 20 orang bagi peniaga dan 80 orang responden dalam kalangan pengunjung di kawasan kajian. Jumlah responden yang dipilih pengkaji adalah berasaskan kepada formula pengiraan saiz sampel oleh Krejcie dan Morgan (1970) seperti berikut:

Pengiraan Saiz Sampel Peniaga:

$$
\begin{gathered}
\mathrm{s}=\frac{x^{2} N P(1-P)}{d^{2}(N-1)+x^{2} P(1-P)} \\
\mathrm{s}=\frac{3.841(20)(0.5)(1-0.5)}{0.05^{2}(20-1)+3.841(0.5)(1-0.5)} \\
\mathrm{s}=\frac{3.841(20)(0.5)(0.5)}{0.0025(19)+1.9205(0.5)} \\
\mathrm{s}=\frac{19.205}{1.00775} \\
\mathrm{~s}=19.05 \\
\# \mathrm{~s}=19
\end{gathered}
$$

Pengiraan Saiz Sampel Pengunjung:

$$
\begin{aligned}
& \mathrm{s}=\frac{x^{2} N P(1-P)}{d^{2}(N-1)+x^{2} P(1-P)} \\
& \mathrm{s}=\frac{3.841(100)(0.5)(1-0.5)}{0.05^{2}(100-1)+3.841(0.5)(1-0.5)}
\end{aligned}
$$




$$
\begin{gathered}
\mathrm{s}=\frac{3.841(100)(0.5)(0.5)}{0.0025(99)+1.9205(0.5)} \\
\mathrm{s}=\frac{96.025}{1.20775} \\
\mathrm{~s}=79.5 \\
\# \mathrm{~s}=80
\end{gathered}
$$

$\mathrm{s}=$ saiz sampel yang diperlukan

$\mathrm{N}=$ saiz populasi yang dikenalpasti (20 orang peniaga \& 100 orang pengunjung)

$\mathrm{P}=$ perkadaran populasi diandaikan 0.5 kerana magnitud ini akan menghasilkan saiz sampel yang

maksimum.

$\mathrm{d}=$ darjah ketepatan yang maksimum $(0.05)$

$\mathrm{x}^{2}=$ nilai khi kuasa dua daripada jadual pada darjah kebebasan 1 iaitu 3.841

\section{Kaedah analisis data}

Kutipan data melalui borang selidik direkodkan dan seterusnya dianalisis dengan menggunakan perisian Statistical Package For The Sosial Science (SPPS) versi 22.0. Data yang diperoleh dianalisis secara statistik deskriptif dan analisis tabulasi silang (crosstab) bagi membuat penghuraian tentang maklumat data yang diperoleh melalui penjelasan dalam bentuk jadual, carta, graf dan sebagainya. Bentuk persembahan data ini dapat memudahkan pembaca memahami hasil daripada dapatan kajian yang telah dianalisis.

\section{Dapatan kajian dan perbincangan}

Bahagian ini menerangkan latar belakang responden, tahap kemudahan dan elemen landskap serta hasil analisis soal selidik berkaitan persepsi dan tahap kepuasan terhadap perkhidmatan dan kemudahan serta perancangan dan pengurusan landskap di Dataran 1Malaysia Klebang. Perbincangan memberi fokus kepada penilaian peniaga dan pengunjung terhadap kemudahan yang disediakan dan analisis hubungan antara elemen perancangan dan pengurusan landskap. Peringkat akhir perbincangan memperincikan strategi serta cadangan penambahbaikan perancangan dan pengurusan landskap.

\section{Latar belakang responden}

Kajian ini meliputi dua kategori responden iaitu golongan peniaga dan pengunjung. Seramai 20 orang peniaga dan 80 orang pengunjung dipilih secara rawak untuk ditemu ramah berdasarkan soal selidik yang diedar. Data bilangan pengunjung yang dapat dianalisis hanyalah sebanyak 60 sahaja disebabkan 20 borang terutamanya bagi kategori kumpulan umur 50 tahun ke atas rosak dan tidak lengkap. Latar belakang responden seperti paparan dalam Jadual 1. Ciri latar belakang responden meliputi kategori yang telah ditetapkan iaitu jantina, kumpulan umur, taraf perkahwinan, etnik, taraf pendidikan, pekerjaan, pendapatan, tempat tinggal dan bilangan pengunjung bersama.

Jadual 1. Data demografi responden

\begin{tabular}{llcccc}
\hline Kategori & Subkategori & \multicolumn{2}{c}{ Peniaga } & \multicolumn{2}{c}{ Pengunjung } \\
\cline { 3 - 6 } & Bilangan & $\begin{array}{c}\text { Peratusan } \\
(\boldsymbol{\%})\end{array}$ & Bilangan & $\begin{array}{c}\text { Peratusan } \\
(\boldsymbol{\%})\end{array}$ \\
\hline Jantina & Lelaki & 8 & 40 & 31 & 51.7 \\
& Perempuan & 12 & 60 & 29 & 48.3
\end{tabular}




\begin{tabular}{|c|c|c|c|c|c|}
\hline Kumpulan & $10-19$ & - & - & 5 & 8.3 \\
\hline \multirow[t]{4}{*}{ Umur } & $20-29$ & 5 & 25 & 27 & 45 \\
\hline & $30-39$ & 9 & 45 & 23 & 38.3 \\
\hline & $40-49$ & 4 & 20 & 5 & 8.3 \\
\hline & 50 tahun ke atas & 2 & 10 & - & - \\
\hline Taraf & Bujang & 3 & 15 & 32 & 53.3 \\
\hline Perkahwinan & Berkahwin & 17 & 85 & 28 & 46.7 \\
\hline \multirow[t]{3}{*}{ Etnik } & Melayu & 20 & 100 & 53 & 88.3 \\
\hline & Cina & - & - & 4 & 6.7 \\
\hline & India & - & - & 3 & 5 \\
\hline Pendapatan & $0-500$ & - & - & 28 & 46.7 \\
\hline \multirow[t]{9}{*}{ Bulanan (RM) } & $501-1000$ & 19 & 95 & 4 & 6.7 \\
\hline & $1001-1500$ & - & - & 13 & 21.7 \\
\hline & $1501-2000$ & 1 & 5 & 8 & 13.3 \\
\hline & $2001-2500$ & - & - & 1 & 1.6 \\
\hline & $2501-3000$ & - & - & 1 & 1.6 \\
\hline & $3001-3500$ & - & - & 1 & 1.6 \\
\hline & $3501-4000$ & - & - & 2 & 3.3 \\
\hline & $4001-4500$ & - & - & 1 & 1.6 \\
\hline & $4501-5000$ & - & - & 1 & 1.6 \\
\hline \multirow[t]{2}{*}{ Tempat Tinggal } & Melaka & 20 & 100 & 50 & 83.3 \\
\hline & Luar Melaka & - & - & 10 & 16.7 \\
\hline Bilangan & $1-3$ Orang & - & - & 38 & 63.3 \\
\hline Pengunjung & $4-6$ Orang & - & - & 21 & 35 \\
\hline Bersama & $7-9$ Orang & - & - & 1 & 1.7 \\
\hline
\end{tabular}

Sumber: Kajian Lapangan (2017)

Persepsi responden terhadap perkhidmatan dan kemudahan di Dataran 1Malaysia Klebang, Melaka

Perkhidmatan dan kemudahan yang disediakan memainkan peranan yang sangat penting bagi menarik dan menggalakkan pengunjung untuk datang ke sesuatu kawasan rekreasi. Antara elemen perkhidmatan dan kemudahan yang utama meliputi aspek keselesaan, kebersihan, keselamatan dan keperluan pengunjung. Hasil analisis data yang diperoleh menerangkan persepsi responden terhadap perkhidmatan dan kemudahan yang disediakan di Dataran 1Malaysia Klebang, Melaka.

a. Kemudahan yang disediakan memenuhi keselesaan

Elemen keselesaan dibahagikan kepada empat iaitu struktur binaan yang kukuh, kedudukan yang strategik, keluasan yang selesa serta persekitaran yang teduh dan redup. Majoriti responden bersetuju bahawa kemudahan yang disediakan di Dataran 1Malaysia Klebang memenuhi keselesaan mereka. Pandangan responden terhadap struktur binaan yang kukuh dan selamat digunakan adalah sebanyak 67.5 peratus bersetuju manakala hanya 6.3 peratus responden tidak bersetuju. Keadaan ini menunjukkan struktur binaan adalah berkualiti dan memberi keselesaan kepada pengguna. Dari segi kedudukan kawasan pula, 71.3 peratus responden bersetuju dan 25.7 peratus sangat setuju bahawa kedudukan Dataran 1Malaysia Klebang, Melaka adalah strategik. Hal ini kerana kedudukannya yang berada di kawasan tumpuan pelancongan di sepanjang pantai Klebang memudahkan pengunjung mencari lokasinya dengan mudah.

Selain itu, kawasan kajian yang terletak berdekatan dengan kawasan tumpuan seperti Coconut Shake Klebang iaitu gerai yang tular menjual air kelapa aiskrim juga membuatkan kawasan ini mudah dikunjungi pengunjung. Kesemua responden bersetuju bahawa keluasan taman rekreasi di Dataran 1Malaysia Klebang memberi keselesaan kepada pengunjung untuk 
melakukan aktiviti riadah iaitu sebanyak 78.8 peratus setuju, 11.3 peratus sangat setuju, manakala 10 peratus memberi respon sederhana setuju. Antara aktiviti riadah yang biasa dilakukan oleh pengunjung yang datang adalah seperti bermain layang- layang, menunggang kuda padi, menaiki kuda dan bermain ATV, Walau bagaimanapun, majoriti responden yang ditemu ramah menyatakan mereka tidak bersetuju dengan persekitaran dataran yang teduh dan redup memberi keselesaan untuk beriadah. Peratusan respon yang diberi adalah sebanyak 45 peratus tidak setuju manakala 28.7 peratus bersetuju menyatakan persekitaran Dataran 1Malaysia Klebang adalah teduh dan redup. Keadaan ini menunjukkan kawasan Dataran 1Malaysia ini kurang terdapat pokok peneduh dan jenis tanaman yang memberi teduhan (Rajah 2).

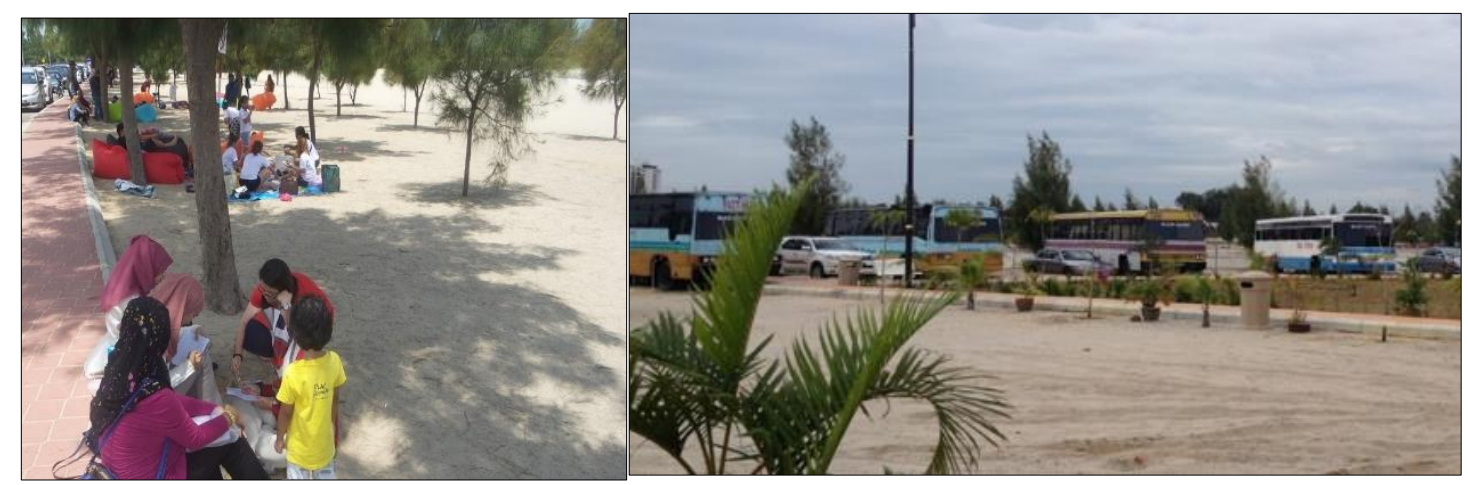

Sumber: Kajian lapangan (2017)

Rajah 2. Kekurangan kawasan rehat dan pokok peneduh

\section{b. Perancangan pengurusan landskap lembut dan kejur}

Hasil dari tinjauan di kawasan kajian didapati susunan dan kedudukan tanaman kurang teratur dan mewujudkan imej kawasan yang suram. Pengekalan kawasan hijau dengan 70 peratus dari keseluruhan ruang taman rekreasi terdiri daripada elemen landskap lembut merupakan garis panduan yang perlu dituruti dalam perancangan dan pengurusan landskap. Ini kerana pengekalan 70 peratus kawasan hijau di sesuatu kawasan rekreasi akan mewujudkan kawsan tersebut berada dalam keadaan tenang dan nyaman. Dapatan kajian menunjukkan persepsi yang kurang memuaskan iaitu seramai 38.8 peratus responden tidak bersetuju dan 40 peratus menyatakan sederhana setuju terhadap konsep berkenaan. Maklum balas responden terhadap perancangan dan pengurusan landskap lembut juga menunjukkan majoriti dari mereka berpendapat bahawa perletakan rekabentuk landskap kurang harmoni dan tiada keserasian antara setiap elemen landskap serta kurang terdapat pokok peneduh yang menyebabkan kawasan panas dan kurang selesa.

Hasil kutipan data berkenaan persepsi responden terhadap perancangan dan pengurusan landskap kejur yang terdiri daripada kemudahan fasiliti, elemen perabot taman, gabungan elemen landskap kejur dan landskap lembut, perabot taman dan kelebaran laluan pejalan kaki. Sebanyak 52.5 peratus responden menyatakan bersetuju dengan kemudahan fasiliti yang disediakan seperti tandas, gerai makanan, tempat letak kenderaan dan sebagainya adalah mencukupi. Sebaliknya, bagi elemen perabot taman seperti gazebo, laluan pejalan kaki dan tempat duduk pula menunjukkan 56.3 peratus responden tidak bersetuju bahawa ia mencukupi untuk pengunjung. Kemudahan seperti tempat duduk yang terhad menyebabkan keberadaan pengunjung di kawasan kajian amat singkat disebabkan oleh faktor yang tidak selesa. Sementara itu, dapatan kajian menunjukkan sebanyak 51.2 peratus responden 
bersetuju dan 32.5 peratus sangat setuju dengan penggunaan elemen landskap kejur yang direkabentuk dan digabungkan dengan elemen landskap lembut.

Rezab landskap yang meliputi kawasan siar kaki dan kawasan penanaman perlu disediakan di kedua-dua belah jalan mengikut kelebaran jalan. Bagi memastikan pertumbuhan tanaman yang baik, rezab landskap pinggir jalan mestilah berukuran minimum tiga meter lebar dan bagi pembahagi jalan mestilah berukuran dua meter (Jabatan Landskap Negara, 2008). Landskap di kawasan jalan juga dapat diperkuatkan dengan kombinasi eleman landskap kejur seperti papan tanda, siar kaki dan perabot landskap yang lain (Rajah 3).

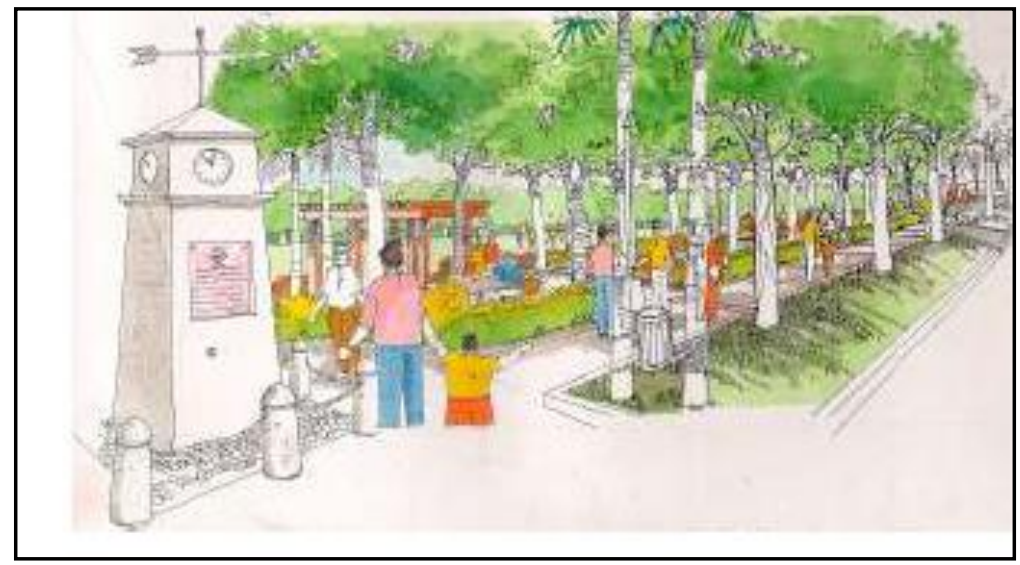

Sumber: Jabatan Landskap Negara (2008)

Rajah 3. Elemen kejur yang dicadangkan di pinggiran jalan

Gabungan kedua-dua elemen ini adalah bagi mewujudkan kawasan persekitaran rekreasi yang harmoni. Kedua-dua jenis landskap ini juga memainkan peranan penting dalam membina sesebuah landskap agar sesebuah landskap itu tidak terlalu kejur dan tidak terlalu lembut. Oleh yang demikian kedua-dua jenis landskap akan digunakan untuk menghasilkan pemandangan yang menarik dan indah dipandang.

c. Kemudahan yang disediakan mencapai tahap kebersihan yang memuaskan

Perkhidmatan dan kemudahan yang disediakan di sesuatu kawasan rekreasi mestilah mematuhi tahap kebersihan seperti yang telah digariskan oleh PBT. Dalam hal ini PBT yang bertanggungjawab adalah MBMB. Terdapat empat kriteria tahap kebersihan dikemukakan kepada responden iaitu kebersihan keseluruhan dataran, penyediaan tong sampah, kebersihan tandas dan pemotongan rumput secara berjadual.

Dapatan kajian menunjukkan terdapat pelbagai reaksi daripada responden iaitu peniaga dan pengunjung terhadap tahap kebersihan di Dataran 1Malaysia Klebang, Melaka. Dari segi tahap kebersihan keseluruhan kawasan dataran, majoriti responden bersetuju ia mencapai tahap kebersihan yang memuaskan iaitu 73.8 peratus menyatakan setuju dan 8.8 peratus menyatakan sangat setuju. Sementara itu, sebanyak 46.3 peratus responden menyatakan tidak bersetuju dan 2.5 peratus sangat tidak setuju berkenaan penyediaan tong sampah di setiap penjuru taman rekreasi. Hal ini berikutan mereka berasa kemudahan tong sampah yang disediakan tidak mencukupi serta berada pada tempat yang kurang sesuai.

Selain itu, sebanyak 46.3 peratus responden bersetuju dan 41.3 peratus sederhana bersetuju terhadap tahap kebersihan tandas di Dataran 1Malaysia Klebang, Melaka. Keadaan ini menunjukkan bahawa keadaan tandas kurang diselenggara dengan baik. Hal ini kerana terdapat tisu yang tidak dibuang dengan sempurna ke dalam tong sampah dan keadaan tandas juga berada dalam keadaan kurang bersih. Hal ini turut dibangkitkan oleh mantan Perdana Menteri Ke-7 iaituYang Berbahagia Tun Dr. Mahathir Mohamad bahawa beliau malu dengan 
keadaan tandas awam di negara ini yang kotor dan busuk yang menurutnya mencerminkan masyarakat Malaysia tidak mempunyai tanggungjawab sivik (Bernama, 2019). Begitu juga dengan respon peniaga dan pengunjung terhadap keadaan rumput di kawasan dataran, sebanyak 68.8 peratus responden menyatakan tahap persetujuan mereka pada tahap memuaskan dan hanya 23.8 peratus bersetuju rumput sentiasa dipotong mengikut jadual secara berkala. Situasi ini digambarkan oleh responden terutama para peniaga yang berada di situ setiap masa.

\section{Strategi perancangan dan pengurusan landskap yang efektif dan efisien}

Perancangan dan pengurusan landskap yang bersistematik mampu meningkatkan kualiti penampilan dan jangka hayat sesuatu kawasan rekreasi. Perancangan dan pengurusan landskap yang sistematik dan terperinci boleh mengurangkan kemusnahan alam sekitar, meningkatkan kualiti hidup, meningkatkan pengalaman pengguna dan meningkatkan keindahan landskap. Berdasarkan hasil kajian berkaitan persepsi masyarakat terhadap perancangan dan pengurusan landskap di Dataran 1Malaysia Klebang, Melaka dapat dirumuskan bahawa perancangan dan pengurusan landskap merupakan satu keperluan utama dalam mewujudkan persekitaran kawasan rekreasi dan interaksi sosial yang kondusif. Pembangunan landskap yang dilaksanakan secara tidak terancang dan kurang sempurna boleh menjejaskan prestasi pembangunan landskap dan menyebabkan kawasan tersebut terjejas. Bagi mengelakkan perkara ini berlaku beberapa pendekatan dan strategi diperlukan sebagai langkah mewujudkan persekitaran yang kondusif.

\section{a. Kemudahan infrastruktur}

Kemudahan infrastruktur merupakan salah satu faktor yang perlu diambilkira. Ini kerana kemudahan yang baik dan sempurna akan menentukan jumlah kedatangan para pelancong ke kawasan dataran mahupun sesebuah kawasan pelancongan. Hasil dari pengamatan pengkaji mendapati kemudahan infrastruktur dan perabot landskap di kawasan kajian amat terhad dan kurang sempurna. Oleh itu perabot landskap yang terdiri daripada gazebo, bangku, pergola, bollard dan tong sampah perlu disediakan di kawasan yang sesuai. Selain itu, penyediaan papan tanda atau arahan grafik yang bersesuaian perlu disediakan bagi memudahkan para pengunjung. Dari segi kemudahan fasiliti seperti menambah bilangan tandas awam dan menyediakan aktivivti riadah iaitu outdoor gym di kawasan kajian bagi keselesaan dan keperluan pengunjung dan peniaga.

\section{b. Perkhidmatan}

Dataran 1Malaysia Klebang, Melaka merupakan sebuah kawasan pelancongan rekreasi. Sistem perkhidmatan perlu dititikberatkan terutamanya daripada segi penginapan seperti bustel bagi meningkatkan bilangan pengunjung. Ia juga merupakan salah satu faktor yang memberikan kepuasan kepada para pengunjung atau pelancong terhadap percutian mereka di kawasan dataran tersebut. Selain itu, kawasan perniagaan juga perlu ditambah baik dari segi perancangan dan pengurusan landskap. Hasil daripada kajian ini menunjukkan tarikan seperti bustel dan kedai makan dalam bas merupakan daya tarikan utama para pengunjung ke dataran tersebut. Oleh itu tarikan seperti ini perlu dikekalkan. Kawasan perniagaan juga perlu ditambahbaik seperti penyediaan ruang makan untuk pengunjung. Selain itu, harga makanan juga perlu dikawal bagi mengalakkan lebih ramai pengunjung ke sini. Kepelbagaian pokok peneduh juga perlu diambilkira. Langkah ini bagi memastikan kawasan Dataran 1 Malaysia Klebang, Melaka berkeadaan redup dan teduh. 


\section{c. Keselamatan}

Aspek keselamatan di kawasan rekreasi perlu diberikan fokus utama oleh setiap individu bagi mengelakkan sebarang musibah yang tidak dijangka berlaku. Hasil dari kajian yang dijalankan mendapati aspek keselamatan kurang diutamakan. Hal ini akan menyebabkan kawasan Dataran 1Malaysia Klebang, Melaka kurang dikunjungi. Bagi mengelakkan perkara in berlaku, aspek keselamatan perlu dipergiatkan seperti meningkatkan aspek keselamatan pejalan kaki dengan menyediakan siar kaki minimum berukuran 1.5 meter bagi memudahkan pergerakan pengunjung. Laluan pejalan kaki yang mempunyai rekabentuk yang sesuai untuk orang kelainan upaya (OKU) seperti orang buta dan cacat anggota yang menggunakan kerusi roda dan tongkat juga perlu disediakan. Selain itu, kemudahan lampu jalan dan lampu taman juga perlu di pertingkatkan bagi tujuan pencahayaan dan keselamatan khususnya pada waktu malam.

\section{Keindahan persekitaran}

Kebersihan merupakan faktor penting dalam mengekalkan keindahan dan pemandangan yang menarik di sesebuah kawasan terutamanya pusat rekreasi. Ini kerana ia merupakan salah satu faktor kepada kedatangan pelancong tempatan mahupun asing ke kawasan tersebut. Oleh yang demikian, sesebuah kawasan rekreasi perlulah di jaga serta dipelihara dengan baik selain memelihara keindahan kawasan itu. Tugas memelihara serta memulihara dalam mengekalkan keindahan alam semula jadi adalah tanggungjawab bersama antara pengunjung dan PBT. Oleh itu, kesedaran orang ramai tentang penjagaan serta pemeliharaan keindahan alam semula jadi perlu dipertingkatkan serta diperluaskan supaya orang ramai mempunyai kesedaran sivik terhadap alam semula jadi.

\section{Implikasi kajian}

Secara umumnya, perlaksanaan pengurusan dan perancangan landskap di Dataran 1Malaysia Klebang, Melaka masih berada di tahap sederhana. Berdasarkan hasil analisis kajian mendapati bahawa perancangan dan pengurusan landskap yang lemah memberi impak kepada kedatangan pengunjung dan juga ke atas pendapatan peniaga. Seterusnya, kajian ini juga menunjukkan bahawa pemantauan dan perancangan daripada PBT adalah penting agar masalah landskap yang wujud di Dataran 1Malaysia Klebang, Melaka dapat diatasi segera. Dapatan kajian juga telah membuktikan bahawa pelaksanaan landskap di Dataran 1Malaysia Klebang, Melaka kurang mengikut garis panduan landskap yang telah dirancang.

Oleh hal demikian, pelaksanaan pembangunan landskap pada masa akan datang perlulah dirancang dan mengikut setiap garis panduan landskap yang telah ditetapkan. Hubungan antara pihak berwajib dan masyarakat merupakan perkara asas utama dalam mengurus tadbir sesebuah pembangunan rekreasi agar persekitaran fizikal dan kesejahteraan masyarakat terjamin kelestariannya.

\section{Kesimpulan}

Pembangunan landskap di Dataran 1Malaysia Klebang, Melaka memerlukan perlaksanaan yang teliti dalam perancangan dan pengurusan landskap bagi mewujudkan pembangunan landskap yang mampan. Kejayaan pembangunan landskap sesebuah kawasan rekreasi boleh dilihat dengan peningkatan jumlah pengunjung yang datang. Selain itu, kolaborasi antara semua pihak termasuk pihak pengurusan dan pengunjung adalah perlu bagi mencapai hasrat 
ini. Oleh hal demikian, perancangan pembangunan landskap yang sistematik dan efektif mampu meningkatkan kualiti hidup masyarakat dan memberi manfaat bukan sahaja dari aspek rekreasi malahan dari aspek kesihatan, keindahan dan juga sosioekonomi.

Pendekatan utama bagi menghasilkan strategi ini ialah melalui penyediaan infrastruktur hijau yang berkesan akan mewujudkan pembangunan kawasan rekreasi yang menarik dan selesa. Pengekalan ruang-ruang hijau di kawasan rekreasi juga mampu berfungsi sebagai kawasan rekreasi dan interaksi sosial dalam melahirkan rakyat yang muhibbah, harmoni, bersatu padu dan sihat sejahtera. Melalui pendekatan ini, strategi pembangunan yang direncanakan untuk keperluan masyarakat akan memberi impak keberhasilan pewujudan persekitaran kehidupan yang lebih kondusif dan kos efektif bagi memastikan kesan yang dihasratkan oleh pihak berwajib dapat dikecapi oleh segenap lapisan masyarakat. Justeru, kepentingan perancangan dan pengurusan landskap dalam pembangunan sesuatu kawasan perlu diberi penekanan yang sewajarnya agar pembangunan tersebut dapat diimbangi dengan pembangunan landskap yang indah, berkualiti dan beridentiti.

\section{Rujukan}

Abdul Haris, S. (2013). Landscape management: An effective landscape management and maintenance. Shah Alam: Penerbit UiTM.

Angelstam, P., Barnes, G., Elbakidze, M., Marsh, A., Marais, C., Mills, A., Polonsky, S., Richardson, D.M., Rivers, N., Shackleton, R., \& Stafford, W. (2017). Collaborative learning to unlock investments for functional ecological infrastructure: Bridging barriers in social-ecological systems in South Africa. Ecosyst Serv, 27, 291-304.

Angelstam, P., Elbakidze, M., Lawrence, A., Manton, M., Melecis, V., \& Pereira, A. (2018). Barriers and bridges for landscape stewardship and knowledge production to sustain functional green infrastructures. In: Pereira, A., Peterson, U., Pastur, G., Iverson, L., \& Plieninger, T. (eds), Sustaining ecosystem services in forest landscapes (pp. 127167). Dordrecht: Springer.

Angelstam, P., Manton, M., Elbakidze, M. (2019). LTSER platforms as a place-based transdisciplinary research infrastructure: Learning landscape approach through evaluation. Landscape Ecol, 34, 1461-1484.

Bernama. (2019). Kebersihan tandas awam tanggungjawab bersama: Muhammad Bakhtiar. $\begin{array}{lllll}\text { BERNAMA. } & 25 & \text { Ogos } & 2019 & \end{array}$ https://www.sinarharian.com.my/article/44702. 02.03.2020.

Bieling, C. \& Plieninger, T. (eds). (2017). The science and practice of landscape stewardship. Cambridge: Cambridge University Press.

Dearden, P. (1981) Public participation and scenic quality analysis. Landscape Planning, 8, 3-19.

Deborah, K. \& Andrew, M. (2008). Visitor perceptions of the benefits of a local park. Pennsylvania, US: Recreation, Park and Tourism Management the Pennsylvania State University.

Deng, X., Li, Z., \& Gibson, J. (2016). A review on trade-off analysis of ecosystem services for sustainable land-use management. J Geogr Sci, 26(7), 953-968.

Er, A.C., Nur Azlin, M.A., \& Mohd Fakhrulrazi, S. (2009). Kesedaran awam terhadap pemeliharaan dan pemuliharaan alam semula jadi: Kes Taman Wetland, Putrajaya. Geografia-Malaysian Journal of Society and Space, 11(8),13-26.

Fischer, A.P., Klooster, A., \& Cirhigiri, L. (2019). Cross-boundary cooperation for landscape management: Collective action and social exchange among individual private forest landowners. Landscape and Urban Planning, 188, 151-162. 
Jabatan Landskap Negara. (2008). Garis panduan landskap negara (Edisi Ke-2). Diperoleh daripada http://jln.kpkt.gov.my/index.php/pages/view/58

Goh, H.C. \& Noratiqah, M. (2016). The user's perceptions of Perdana Botanical Garden in Kuala Lumpur. Journal of Design and Built Environment, 16(1), 27-36.

Jansson, M., Vogel, N., Fors, H. \& Randrup, T.B. (2019). The governance of landscape management: New approaches to urban open space development. Landscape Research, 44(8), 952-965.

Jubenville, A. \& Ben, W.T. (1993). Outdoor recreation (Ed ke-3). USA: Venture Publishing Inc State College.

Krejcie, R.V. \& Morgan, D.W. (1970). Determining sample size for research activities. Educational and Phychological Measurement, 30, 607-610.

Locatelli, B., Lavorel, S., Sloan, S., Tappeiner, U., \& Geneletti, D. (2017). Characteristic trajectories of ecosystem services in mountains. Front Ecol Environ, 15(3),150-159.

More, T.A. (1989). Factors affecting the productivity of urban parks. Research paper, Department of Agriculture, US. Diperoleh daripada https://www.fs.fed.us/ne/ newtown_square/publications/research_papers/pdfs/scanned/OCR/ne_rp630.pdf

Noralizawati, M. \& Noriah, O. (2010). Push and pull factor: Determining the visitors' satisfactions at urban recreational area. Procedia - Social and Behavioral Sciences, 49, $175-182$.

Osman, M.T. (2002). Pembudayaan landskap berkualiti pemangkin kehidupan dan persekitaran berkualiti. Serdang: Fakulti Rekabentuk dan Senibina, Universiti Putra Malaysia.

Potschin, M. \& Haines-Young, R. (2013). Landscapes, sustainability and the place-based analysis of ecosystem services. Landscape Ecol, 28(6), 1053-1065.

Rosniza Aznie, C.R. \& Nur Efazainiza Ainie, B. 2019. Analisis tahap kepuasan pengunjung di taman rekreasi awam Sabah. Geografia-Malaysian Journal of Society and Space, 15(4), 336-349.

Thompson, J.W. \& Sorvig, K. 2000. Sustainable landscape construction: A guide to green building outdoors. Washington DC: Island Press.

Verbrugge, L., Buchecker, M., \& Garcia, X. (2019). Integrating sense of place in planning and management of multifunctional river landscapes: Experiences from five European case studies. Sustain Sci, 14, 669-680.

Wan Mohammad, W.M. (1995). Quality sports and recreational facilities for effective utilization. Kertas kerja dibentangkan di Seminar Kemudahan Sukan di UiTM Shah Alam, Selangor. 13-15 Jun 1995. 